\title{
HOW TO WRITE A SCIENTIFIC RESEARCH PAPER
}

\section{Kashif Asghar, Muhammad Usman Rashid}

Department of Basic Sciences Research, Shaukat Khanum Memorial Cancer Hospital and Research Centre, Lahore, Pakistan

Received: 21 July 2017 / Accepted: 15 September 2017

The main task of a researcher is a communication of technical results to the scientific community. Scientific communication is a fundamental step in the scientific method. A poor idea or a poorly planned investigation cannot be saved by an outstanding presentation, and equally an exceptional idea that is well investigated can still be ruined by a poor presentation. In other words, a good researcher should be a good communicator as well.

\section{Writing process}

Pre-writing: Review literature, make notes, start generating novel ideas, draw figures and focus ones writing as per audience.

Writing: Organise the ideas and notes into structured paragraphs and keep writing.

Revision: Concentrate on the basic concept, communication, reasoning and flow.

Editing: Analyse the data for accuracy and review for the grammatical and technical errors.

Proofreading: Print and carefully read the draft again and again and further share with other co-authors of this manuscript.

\section{Structure}

Writing a scientific paper is an art. Scientific research must initiate with a well-defined research question. Developing a researchable question is one of the crucial steps a researcher faces when initiating a project. A clinical question needs to be relevant to the patient or problem at hand and phrased in such a way as to help the

Correspondence: Dr. Kashif Asghar, Department of Basic

Sciences Research, Shaukat Khanum Memorial Cancer Hospital and

Research Centre, Lahore, Pakistan.

Email: kashifasghar@skm.org.pk search for an answer. Population, intervention, control and outcomes makes this process easier. ${ }^{[1]}$ Poor reporting hinders the evaluation of the strengths and weaknesses of a study.

A group of methodologists, researchers and editors developed the 'Strengthening the Reporting of Observational Studies in Epidemiology' (STROBE) and the 'Consolidated Standards of Reporting Trials' (CONSORT) recommendations to improve the quality of reporting of observational studies and trials. ${ }^{[2,3]}$

PubMed, Google Scholar, Science Direct etc. are wellknown search engines for biomedical literature search. This groundwork is based on the data from which the manuscript can be created. Writing a good scientific manuscript needs intense attentiveness and brain work. As stated in Hayes' framework for the study of writing: "It is a generative activity requiring motivation, and it is an intellectual activity requiring cognitive processes and memory." ${ }^{,[4]}$ Once a research work is complete, a sensible technique of writing a scientific research paper may involve the following. First draft the methods section. Compose all figures and/or tables and then write the results section. Carefully evaluate the scientific questions and then write the introduction section. Next is to write the discussion section using the introduction and results' sections. Summarise all the stuff in an abstract section, and then recapitulate the abstract into the conclusion section.

\begin{tabular}{l|l}
\hline Experimental process & Division of paper \\
\hline What is the study theme? & Title \\
\hline What is the problem? & Introduction \\
\hline How did we resolve the problem? & $\begin{array}{l}\text { Materials and } \\
\text { Methods }\end{array}$ \\
\hline What did we find out? & Results \\
\hline What does it mean? & $\begin{array}{l}\text { Discussion/Conclu- } \\
\text { sion }\end{array}$ \\
\hline Summarise all the above sections? & Abstract \\
\hline
\end{tabular}




\begin{tabular}{l|l}
\hline Who helped us out? & $\begin{array}{l}\text { Acknowledgements } \\
\text { (optional) }\end{array}$ \\
\hline Whose work did we refer to? & References \\
\hline Additional information & $\begin{array}{l}\text { Appendices } \\
\text { (optional) }\end{array}$ \\
\hline
\end{tabular}

\section{Study title}

Every scientific manuscript must have a self-explanatory title. When generating a title, express the subject but do not try to impress the reader with too many technical details. The main aim of a title should be to communicate the information. The title must be precise and unambiguous and should clearly mention the authors and authors' affiliations. Select the journal to keep in view the focus of the manuscript. Finally, mention the corresponding author's email address.

Example title:

Rashid et al BMC Cancer 2013, 13:312

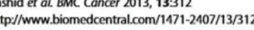

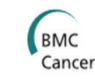

RESEARCH ARTICLE

Open Access

Constitutional CHEK2 mutations are infrequent in early-onset and familial breast/ovarian cancer patients from Pakistan

Muhammad U Rashid ${ }^{12}$, Noor Muhammad', Saima Faisal', Asim Amin ${ }^{3}$ and Ute Hamann ${ }^{2 *}$

\section{Abstract}

It is usually one paragraph summary of the entire paper. However, a number of paragraph(s) should be according to the journal's instructions to the authors. An abstract should be self-explanatory without reference to the paper but is not an alternate for the paper. The abstract should be no more than 250 words. Write an abstract in passive voice and use active voice only when required. The first few sentences should state the background and objective of the experiment. The abstract must concisely explain the scientific question of the paper, materials and methods, results and conclusions. Do not include the detailed descriptions of materials and methods. Tables, figures or references or references to literature cited usually are not a part of this section. The abstract is usually written after the write up of the whole manuscript. The abstract should be written in the following prescribed sequence:

- State the purpose of research unambiguously in the first or second sentence (from introduction)
- Describe the experimental design and methodology without going into the excessive details (from methods)

- Report those results that address the questions that were asked in the beginning (from results)

- Interpret the results and state the conclusion (from discussion).

The final sentences should clearly mention the significance of the results. The abstract should contain approximately 3-4 key words.

Example abstract:

\section{Background}

Less than $20 \%$ of Pakistani women with early-onset or familial breast/ovarian cancer harbour germline mutations in the high-penetrance genes such as BRCA1, $B R C A 2$ and TP53. Thus, mutations in other genes confer genetic susceptibility to breast cancer, of which CHEK2 is a plausible candidate. $C H E K 2$ encodes a checkpoint kinase, involved in response to DNA damage.

\section{Methods}

In the present study, we assessed the prevalence of CHEK2 germline mutations in 145 BRCA1/2-negative early-onset and familial breast/ovarian cancer patients from Pakistan (Group 1). Mutation analysis of the complete $C H E K 2$ coding region was performed using denaturing high-performance liquid chromatography analysis, followed by DNA sequencing of variant fragments.

\section{Results}

Two potentially deleterious missense mutations, c. $275 \mathrm{C}>\mathrm{G}$ (p.P92R) and c. 1216C $>$ T (p.R406C), were identified (1.4\%). The c. $275 \mathrm{C}>\mathrm{G}$ mutation is novel and has not been described in other populations. It was detected in a 30 -year-old breast cancer patient with a family history of breast and multiple other cancers. The c. 1216C $>$ T mutation was found in a 34-year-old ovarian cancer patient from a family with two breast cancer cases. Both mutations were not detected in 229 recently recruited $B R C A 1 / 2$-negative high-risk patients (Group 2). 


\section{Conclusion}

Our findings suggest that CHEK2 mutations may not contribute significantly to breast/ovarian risk in Pakistani women.

Key words: $C H E K 2$, germline mutations, early onset and familial breast cancer, Pakistan

\section{Introduction}

The introduction section needs a brief background and a short review of the literature relating to the research topic. This section should not be more than two pages. The introduction should be written in an inverted triangle format. Start by stating the general information and previous knowledge and then lead the paragraph towards the core concepts that will be studied. In the end, mention the study purpose and rationale. Use active voice as much as possible. It should explain the questions evaluated by experimentation explained in the manuscript and describe why these are important questions.

Amelioration of an aspect of this field is illustrated in the following paragraphs. The introduction should define all the abbreviations that will be used in the manuscript. The final paragraph is critical. It defines what experimental question will be answered in the present study. Identification of hypothesis is followed by summing up methodologies, taken to verify the hypothesis. Finally, a sentence may be added asserting how the answer of research question will be instrumental in the overall field of a study. ${ }^{[5]}$

Introduction should be able to answer the questions such as:

- What was the basis of this study?

- What is the importance of carrying out this research?

- How does this study correlate with the work done before?

- How will this study helps in advancement of current scientific knowledge?

\section{Materials and Methods}

This section should concisely explain about the study population and what was actually performed. It should be comprised of the description of techniques. In the manuscript, a relevant reference should be cited, for example, indicate 'were performed as described by Rashid et al. ${ }^{\left[{ }^{[6]}\right.}$ It is imperative to specify pertinent information about the experiment i.e. final concentrations applied. This information is vital so that readers have the capability to transcribe the experiment in their own establishments. In this section, passive voice predominantly supersedes the use of the active voice. ${ }^{[7,8]}$ Finally, explain the statistical analysis techniques that were utilised to observe the results. Based on experimental conditions and materials used, this section should contain the following information:

- The study subjects including patients (cases), healthy individuals (controls) clinicopathological features, socioeconomic backgrounds, ethnicity, geographic origin and consent forms.

- The experimental and sampling design which includes physical as well chemical conditions. The method of obtaining a sample and its storage should also be included. Experimental conditions such as temperature and pressure are also a part of this section.

- Analysis of data including all the software being applied, statistical and qualitative analyses.

\section{Results}

In the results' section, one should simply present the data extracted from experiments but should not discuss the primary results. ${ }^{[9]}$ In other words, "just describe the facts, please." The experimental data should be supplemented with tables and figures (graphs, photographs, diagrams, etc.). Tables should be self-explanatory. Footnotes should be used in case of any abbreviations or explaining any point. Data displayed in the table should not be subsequently illustrated Example Table 1.

Tables are most useful for

- Documenting data.

- Explicating calculations or presenting components of calculated data.

- Displaying the actual data values.

- Permitting various comparisons between components in many ways.

Keep in mind that it is not the reader's job to figure out what the various figures are trying to demonstrate. Design each figure about the point that needs to be emphasised. 
The variety of figure types permits one to emphasise different qualities of the data. These include:

- Pie charts.

- Column and bar charts.

- Line charts.

- Radar charts.

Figures are most useful for:

- Presenting a complete trend.

- Description of the story through 'shape' rather than the actual statistics.

- Favouring simple correlations between only a few factors.

Figure legends should describe what the data are being presented. The significant points of the manuscript should stand alone i.e., the reader should not need to read the rest of the text to understand them. Figure legends have an overall form with four parts. These parts occur in sequence, but explanation of notation and symbols may be scattered in the other parts.

- Summarise what the figure is about.

- Parts of results shown in the figure.

- Description of the components of the figure, methods used.

Explanation of the units or statistical notation and symbols included.

Poor illustrations can invalidate a comprehensive research by failing to clearly illustrate one's discoveries. In case of experimental studies, statistics i.e., number of samples (n), the index of central tendency and the index of distribution and specific statistical data, such as p-values, confidence interval and statistical method applied, must be indicated. ${ }^{[9]}$

Be succinct. The following things should be avoided while writing the results.

- Do not repeat each value from a figure or table

- Do not report the same data in both a table and figure

- Do not state raw data values when these can be summarised as means and percentages, etc.

\section{Discussion}

In the discussion section, the author(s) should describe the study results and discuss whether the study data support or contradict previously reported findings. The authors should discuss the study major findings. Therefore, undertake the discussion with a condensed paragraph that reiterates overview of work. Elaborate the indispensable findings and, if appropriate, accept or reject the proposed hypothesis. Next, distinguish salient findings that were proposed in the results section, and compare these results with regards to other studies reported in the literature. Use the active voice whenever possible in this section. This section should include thorough citation of the works of other researchers that are mentioned the discussion. The authors should also explain the strengths and weaknesses of their study. Do not introduce the new results in the discussion section. ${ }^{[10]}$

Essential questions to answer:

- Do your results provide answers to your scientific hypotheses? If so, how do you analyse your findings?

- Do your results agree with what others have shown?

- Do your results differ from the previous reports? What are the likely reasons?

- What are study limitations?

- If necessary, what would be the next phase in your study, for example, what experiments would you do in future?

\section{Conclusion}

Initially, propose the work, specifically explain significant findings and then accentuate major discussion points. Finally, conclude with a sentence about how this work contributes to the overall field of the study.

\section{Acknowledgements}

Most scientific research articles include an important section in which the authors thank several people, funding bodies and organisations who have contributed in some way to the work. These contributions could be in helping to form the original hypotheses, collecting data, providing financial aid, etc.

\section{Additional information}

Each journal focuses in a specific area of research. An appropriate selection of journal can make a greater impact of the research work. Always prefer to select 2 or 3 journals in the selected field with relatively high impact factor before submission. Each journal has its own publishing guidelines which describe the structure 
in great detail, for example, font size in table, figures, text and headings. It is imperative for each researcher to thoroughly read the instructions before embarking on writing a manuscript. Falsification, fabrication and plagiarism are the basic concerns in avoiding research misconduct. Falsification is the changing of research data to support hypotheses. Fabrication is the addition of observations that never occurred in the collecting of data or performing of experiments. Plagiarism is using the work of others as one's own work, even if committed unintentionally. It is the most common form of research misconduct. When authors submit a manuscript, they should clearly mention that there is no conflict of interest in the study. The international committee of medical journal editors has developed a form for disclosure of conflicts of interest to standardise authors' disclosures.

\section{References}

It is necessary to acknowledge the published articles stated in your text. There are various ways to cite references in the manuscript and the employed style depends on the instruction of the journal. Different software are available which make citing literature easy, for example, EndNote,
Mendeley and Reference manager. Citations within the text should refer to reference list. Do not mark this section as 'Bibliography'. This section is found in books but not in the scientific research papers.

\section{Appendices}

An appendix comprises information that is not essential to understanding of the paper but may present data that further clarify a point without burdening the body of the manuscript. An appendix is an optional part of the paper. Figures and tables are often found in the appendices, for example, supplementary Figure 1.

Some examples of material that might be placed in an appendix:

- Raw data.

- Additional images.

- Full generic names of chemicals or compounds.

- Diagrams.

\section{Conflict of Interest}

The authors declare that they have no conflict of interest.

Example Table 1: Description of index cases screened for CHEK2 mutations

\begin{tabular}{|c|c|c|c|c|c|c|}
\hline \multirow{2}{*}{$\begin{array}{l}\text { Cancer type } \\
\text { of index case }\end{array}$} & \multirow{2}{*}{$\begin{array}{l}\text { Phenotype of fam- } \\
\text { ilies? }\end{array}$} & \multirow{2}{*}{$\begin{array}{l}\text { Number of } \\
\text { families }\end{array}$} & \multicolumn{2}{|c|}{ Index cases } & \multirow{2}{*}{$\begin{array}{c}\text { Mean age of } \\
\text { index cases in } \\
\text { years (age range) }\end{array}$} & \multirow{2}{*}{$\begin{array}{c}\text { Cases with } \\
\text { mutations } \\
n(\%)\end{array}$} \\
\hline & & & $\begin{array}{c}\text { Unilateral } \\
\text { BC }\end{array}$ & $\begin{array}{l}\text { Bilateral } \\
\text { BC }\end{array}$ & & \\
\hline \multicolumn{7}{|l|}{ Group I } \\
\hline \multicolumn{7}{|l|}{ Female cases } \\
\hline $\mathrm{BC}$ & $\begin{array}{l}\text { Early onset } \\
\text { BC ( } 1 \text { case } \leq 30 \text { years })\end{array}$ & 66 & 66 & - & $27.2(22-30)$ & $1(1.5)$ \\
\hline $\mathrm{BC}$ & $\begin{array}{l}\text { HBC ( } 2 \text { cases, } \geq 1 \\
\text { diagnosed } \leq 50 \text { years) }\end{array}$ & 30 & 17 & 13 & $34.2(22-48)$ & $0(0)$ \\
\hline $\mathrm{BC}$ & $\begin{array}{l}\text { HBC ( } \geq 3 \text { cases, } \geq 1 \\
\text { diagnosed } \leq 50 \text { years) }\end{array}$ & 9 & 5 & 4 & $38.1(24-70)$ & $0(0)$ \\
\hline $\mathrm{BC}$ & HBOC $(\geq 2$ cases $)$ & 2 & 2 & - & $41.5(35-48)$ & $0(0)$ \\
\hline $\mathrm{BC}$ and $\mathrm{OC}^{\mathrm{b}}$ & HBOC ( $\geq 2$ cases) & 4 & 3 & 1 & $31.2(29-34)$ & $0(0)$ \\
\hline $\mathrm{OC}$ & HBOC ( $\geq 2$ cases) & 2 & - & - & $31(28-34)$ & $1(50)$ \\
\hline OC & $\begin{array}{l}\text { Early onset OC ( } 1 \text { case } \\
\leq 45 \text { years) }\end{array}$ & 19 & - & - & $33.2(22-45)$ & $0(0)$ \\
\hline $\mathrm{OC}$ & $\begin{array}{l}\text { HOC ( } 2 \text { cases, } \geq 1 \\
\text { diagnosed } \leq 45 \text { years) }\end{array}$ & 2 & - & - & $34(31-37)$ & $0(0)$ \\
\hline
\end{tabular}




\begin{tabular}{|c|c|c|c|c|c|c|}
\hline \multicolumn{7}{|l|}{ Male cases } \\
\hline $\mathrm{BC}$ & Male BC & 11 & 11 & - & $48(30-73)$ & $0(0)$ \\
\hline All cases ${ }^{c}$ & & 145 & 104 & 18 & & $2(1.4)$ \\
\hline \multicolumn{7}{|l|}{ Group II } \\
\hline \multicolumn{7}{|l|}{ Female cases } \\
\hline $\mathrm{BC}$ & $\begin{array}{l}\text { Early onset } \\
\text { BC ( } 1 \text { case } \leq 30 \text { years })\end{array}$ & 103 & 103 & - & $27.1(19-30)$ & $0(0)$ \\
\hline $\mathrm{BC}$ & $\begin{array}{l}\text { HBC ( } 2 \text { cases, } \geq 1 \\
\text { diagnosed } \leq 50 \text { years) }\end{array}$ & 55 & 49 & 6 & $40.8(19-61)$ & $0(0)$ \\
\hline $\mathrm{BC}$ & $\begin{array}{l}\text { HBC ( } \geq 3 \text { cases, } \geq 1 \\
\text { diagnosed } \leq 50 \text { years) }\end{array}$ & 53 & 47 & 6 & $44.4(26-73)$ & $0(0)$ \\
\hline $\mathrm{BC}$ & HBOC ( $\geq 2$ cases) & 8 & 7 & 1 & $49(26-67)$ & $0(0)$ \\
\hline $\mathrm{BC}$ and $\mathrm{OC}^{\mathrm{b}}$ & HBOC ( $\geq 2$ cases) & 3 & 2 & 1 & $45.6(30-59)$ & $0(0)$ \\
\hline $\mathrm{OC}$ & HBOC ( $\geq 2$ cases) & 5 & - & - & $43.2(33-60)$ & $0(0)$ \\
\hline $\mathrm{OC}$ & $\begin{array}{l}\text { Early onset OC ( } 1 \text { case } \\
\leq 45 \text { years) }\end{array}$ & 2 & - & - & $30.5(25-36)$ & $0(0)$ \\
\hline All cases $^{d}$ & & 229 & 208 & 14 & & $0(0)$ \\
\hline
\end{tabular}

BC: Breast cancer, HBC: Hereditary breast cancer, HBOC: Hereditary breast and ovarian cancer, HOC: Hereditary ovarian cancer, OC: Ovarian cancer. asee 'Study subjects in Method section', 'Breast and ovarian cancer in the same patient was counted as two independent cases, clncluding 111 female BCs, 11 male BCs and $27^{\circ} \mathrm{Cs}$, IIncluding 222 female $\mathrm{BCs}$ and $10^{\circ} \mathrm{Cs}$

\section{Supplementary Figure 1}

A. Family 112, carrier of CHEK2 c.275C $>$ G (p.P92R)

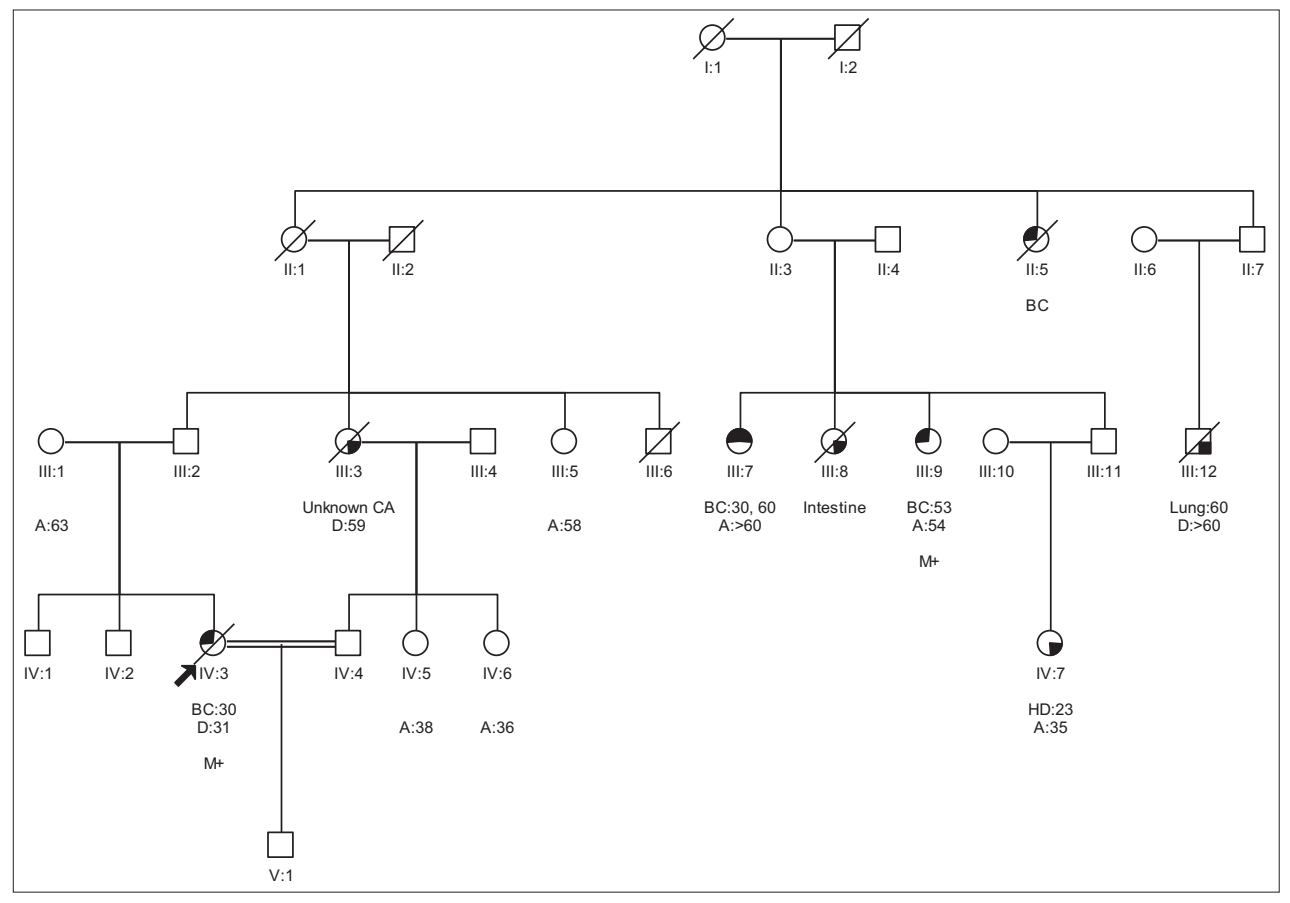




\section{B. Family 171, carrier of $C H E K 2$ c.1216C $>$ T (p.R406C)}

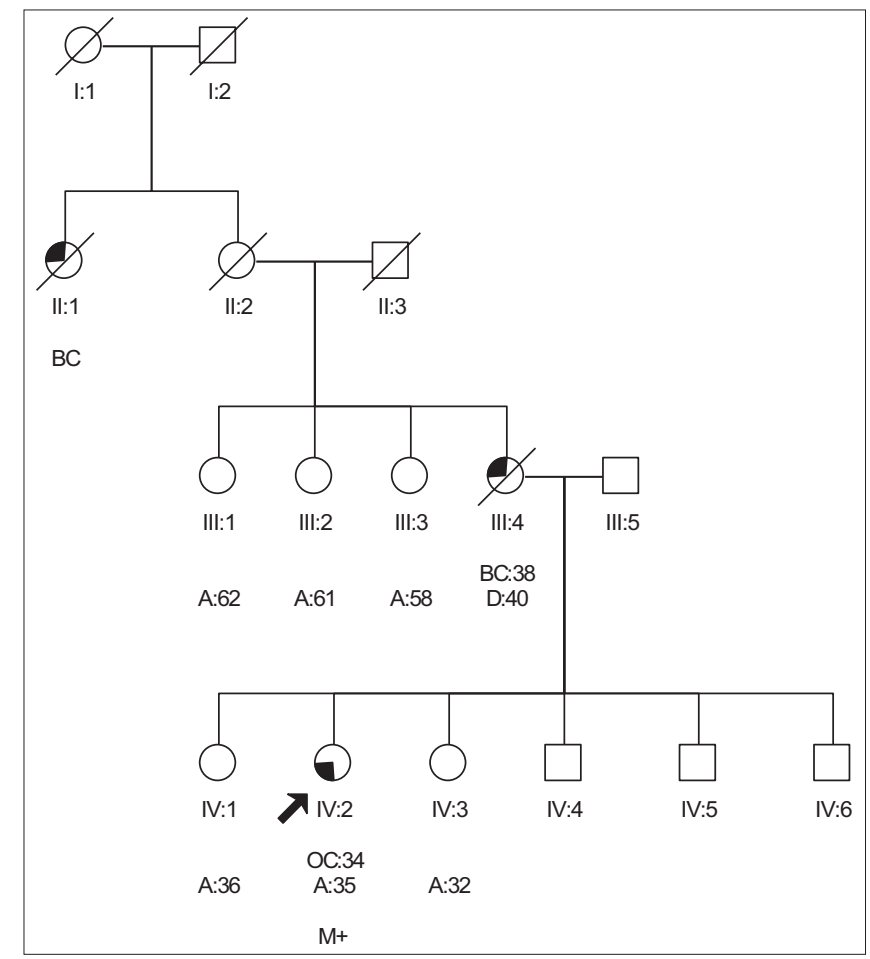

Supplementary Figure 1 Pedigrees of CHEK2 c. 275C $>\mathrm{G}$ (A) and c.1216C $>\mathrm{T}$ (B) mutation carrier Families 112 and 171. Circles are females, squares are males and a diagonal slash indicates a deceased individual. Symbols with filled left upper quadrant: Unilateral breast cancer. Symbols with filled upper half circle: Bilateral breast cancer. Symbols with filled left lower quadrant: Ovarian cancer. Symbols with filled right lower quadrant: Cancer other than breast cancer, cancer type is indicated. Identification numbers of individuals are below the symbols. The index patient is indicated by an arrow. A - Age; BC - Breast cancer; HD - Hodgkin's disease; OC - Ovarian cancer; CA - Cancer; $\mathrm{D}$ - Death. The numbers following these abbreviations indicate age at recruitment, age at cancer diagnosis and age at death. M+ - Mutation positive. $M$ - - Mutation negative.

\section{References}

1. Aslam S, Emmanuel P. Formulating a researchable question: A critical step for facilitating good clinical research. Indian J Sex Transm Dis AIDS 2010;31:47-50.

2. Vandenbroucke JP, von Elm E, Altman DG, et al. Strengthening the reporting of observational studies in epidemiology (STROBE): Explanation and elaboration. Epidemiology 2007;18:805-35.

3. Bolignano D, Mattace-Raso F, Torino C, et al. The quality of reporting in clinical research: The CONSORT and STROBE initiatives. Aging Clin Exp Res 2013;25:9-15.

4. Hayes JR. In: Levy C, Ransdell S, editors. A New Framework for Understanding Cognition and Affect in Writing. Mahwah, NJ: Lawrence Erlbaum; 1996.

5. McMillan VE, McMillan V. Writing Papers in the Biological
Sciences. Boston: Bedford/St. Martin's; 2011.

6. Rashid MU, Muhammad N, Faisal S, et al. Constitutional CHEK2 mutations are infrequent in early-onset and familial breast/ovarian cancer patients from Pakistan. BMC Cancer 2013;13:312.

7. Hofmann AH. Scientific Writing and Communication: Papers, Proposals, and Presentations. New York: Oxford University Press; 2014.

8. Rodman L. The active voice in scientific articles: Frequency and discourse functions. J Tech Writ Commun 1994;24:309-31.

9. Harrison WA $3^{\text {rd }}$, Katharine PA. A Handbook of Biological Investigation. $4^{\text {th }}$ ed. Hunter Textbooks Inc.; 1987.

10. Robert SD. How to Write and Publish a Scientific Paper. $4^{\text {th }}$ ed. Phoenix: Oryx Press; 1994. 